\title{
Open versus laparoscopic appendectomy among Saudi patients
}

\author{
Mohammed Miftah ${ }^{1}$, Jumanh Attiah ${ }^{2}$, Omar Alawaji $^{3}$, Faisal Alghamdi ${ }^{4}$, Abdulaziz Alasmari ${ }^{5}$, \\ Alaa Elsayed ${ }^{6}$, Basil Alfarrah ${ }^{7}$, Malik Almohideb ${ }^{8}$, Rawabi Majrashi ${ }^{5}$, Mohammed Al Adi ${ }^{9}$
}

\author{
${ }^{1}$ Jazan University, Jizan, KSA \\ ${ }^{2}$ Ibn Sina National College for Medical Studies, Jeddah, KSA \\ ${ }^{3}$ Taibah University, Al Madinah, KSA \\ ${ }^{4}$ Air Base Hospital, Dhahran, KSA \\ ${ }^{5}$ Umm AlQura University, Mecca, KSA \\ ${ }^{6}$ Prince Mohammed Bin Abdul Aziz Hospital - Al Madinah, KSA \\ ${ }^{7}$ Almaarefa Colleges, Riyadh, KSA \\ ${ }^{8}$ Imam Muhammad ibn Saud Islamic University, Riyadh, KSA \\ ${ }^{9}$ Imam Abdulrahman Bin Faisal University, Dammam, KSA
}

Received: 19 July 2018

Revised: 18 August 2018

Accepted: 20 August 2018

\section{*Correspondence:}

Dr. Mohammed Miftah,

E-mail: miftah_1982@yahoo.com

Copyright: (C) the author(s), publisher and licensee Medip Academy. This is an open-access article distributed under the terms of the Creative Commons Attribution Non-Commercial License, which permits unrestricted non-commercial use, distribution, and reproduction in any medium, provided the original work is properly cited.

\begin{abstract}
Appendicitis is the most common cause for abdominal surgeries among all age groups worldwide. Significant research papers were published concerning the techniques through which appendectomy is done. Open appendectomy has been the gold standard treatment for acute appendicitis and has been known as a safe practice with relatively low rate of postoperative complications. However, in the last few decades, laparoscopic surgery has developed widely with the advent of minimal surgical invasion and is now more increasingly prevalent intervention. In this study, we aim to report on previous literature on laparoscopic and open appendectomies that were carried out in Saudi Arabia and compare the efficacy, safety and complications of performing laparoscopic and open appendectomies including mean operative time, mean hospital stay and prevalence of postoperative complications, mainly, wound infection and intra-abdominal infections. PubMed database and EBSCO Information Services were used for articles selection. All relevant articles to our review with the topics regarding the appendectomy procedures; both open, laparoscopic, and other articles have been used. We excluded other articles, which are not related to this field. The data will be extracted according to specific form in which it is going to be reviewed by the group members. The study found out that mean operative time was shorter in open procedures than laparoscopic one making it open appendectomy the faster intervention. Mean hospital stay was found to be significantly less in LA than OA patients. Indicated higher rate of intra-abdominal infections in the LA patients than OA ones, while wound infections are mainly present in OA cases in the reference studies.
\end{abstract}

Keywords: Appendicitis, Open appendectomy, Laparoscopic appendectomy, Saudi Arabia

\section{INTRODUCTION}

Appendicitis is known as the most common cause for abdominal surgical procedures among all age groups. ${ }^{1}$ Open appendectomy has been the standard treatment of acute appendicitis for more than a century. Although it is a safe procedure, the incidence of postoperative complications is $10 \%$ to $20 \% .^{2}$ Over the last three decades with the advent of laparoscopic surgery and the more widespread use of laparoscopy, complicated 
appendicitis (CA) defined as gangrenous or perforated appendicitis with or without peritonitis has been increasingly managed laparoscopically, with up to $67 \%$ of cases of CA performed laparoscopically in 2011 in the USA. $^{3}$ Open and laparoscopic approaches are highly equivalent through; however, each approach has its advantages in certain situations. Specific comparative research between both of them have not be run on Saudi patients specifically, but world widely, the open technique is less costly and is associated with shorter operative times. ${ }^{4}$ Laparoscopy allows the doctor to obtain superior visualization of the peritoneal cavity and exclusion of other pathology when the diagnosis of appendicitis is equivocal, thus it is often the operation of choice in women that are of childbearing age in whom the differential diagnosis for appendicitis is broad. ${ }^{5}$ Although the safety of laparoscopic appendectomy is well documented, the superiority of LA over OA has not yet been well established. This is in contrast to laparoscopic cholecystectomies, which are more advantageous over open cholecystectomies. ${ }^{6}$ This study was designed as a review comparative literature to point out the differences between the open and laparoscopic appendectomy in different hospitals and regions of Saudi Arabia.

\section{METHODS}

\section{Sample and study groups}

PubMed and EBSCO Information Services were chosen as the search databases for the publications used within the study, as they are high-quality sources. PubMed being one of the largest digital libraries on the internet developed by the National Center for Biotechnology Information (NCBI) which is a part of the United States National Library of Medicine. Topics concerning the appendectomy procedures; both open, laparoscopic, comparative, and other articles have been used in the making of the article. Restriction to the last 10 years, country restriction on Saudi Arabia, and English language due to unavailable resources for translation were used. The founded articles were screened by titles, and reviewing the abstracts yielded 4 articles which were enrolled.

Inclusion criteria: The articles were selected based on the relevance to the project which should include one of the following topics; 'Open appendectomy, laparoscopic appendectomy, and open versus laparoscopic appendectomy'.

Exclusion criteria: All other articles which did not have one of these topics as their primary end, or repeated studies, and reviews studies have been excluded.

\section{Statistical analysis}

No software has been utilized to analyze the data. The data was extracted based on specific form that contain (Title of the publication, author's name, objective, summary, results, and outcomes). These data were reviewed by the group members to determine the initial findings, and the modalities of performing the surgical procedure. Double revision of each member's outcomes was applied to ensure the validity and minimize the mistakes.

\section{RESULTS}

Nassir et al group, assessed the prevalence of LA with regard to different variables. Their study included 243 patients with acute appendicitis in the period between April and July 2016 in the general surgery department of King Abdulaziz Hospital and Oncology Center in Jeddah, Saudi Arabia. They found that advantages of the laparoscopic appendectomy approach including shorter hospital stay, decreased need for postoperative analgesia, early food tolerance, earlier return to work, lower rate of wound infection. They also found a considerable preference of patients and a high satisfaction after the surgery. $^{7}$

Table 1: Study, study design, country, objective, duration, outcome and reference number.

\begin{tabular}{|c|c|c|c|c|c|c|}
\hline Study & Study design & Country & Objective & $\begin{array}{l}\text { Duration } \\
\text { of study }\end{array}$ & Outcome & Ref. \\
\hline $\begin{array}{l}\text { Nassir et } \\
\text { al }\end{array}$ & $\begin{array}{l}\text { Cross- } \\
\text { sectional study }\end{array}$ & KSA & $\begin{array}{l}\text { Assess the prevalence } \\
\text { of laparoscopic } \\
\text { appendectomy with } \\
\text { regard to several post- } \\
\text { operative variables. }\end{array}$ & 3 months & $\begin{array}{l}\text { Advantages of the laparoscopic } \\
\text { appendectomy approach including } \\
\text { shorter hospital stay, decreased } \\
\text { need for postoperative analgesia, } \\
\text { early food tolerance, earlier return } \\
\text { to work, lower rate of wound } \\
\text { infection. Furthermore a } \\
\text { considerable preference of patients } \\
\text { and a high satisfaction after the } \\
\text { surgery was found. }\end{array}$ & 7 \\
\hline $\begin{array}{l}\text { Al- } \\
\text { Bassam }\end{array}$ & $\begin{array}{l}\text { Cross- } \\
\text { sectional study }\end{array}$ & $\mathrm{KSA}$ & $\begin{array}{l}\text { Examining the efficacy, } \\
\text { safety and } \\
\text { complications of LA in } \\
\text { children. }\end{array}$ & 5 years & $\begin{array}{l}\text { Laparoscopic appendectomy is } \\
\text { both a safe and effective method } \\
\text { in managing children with acute } \\
\text { uncomplicated appendicitis. LA } \\
\text { should be done with caution in } \\
\text { children with complicated } \\
\text { appendicitis. }\end{array}$ & 8 \\
\hline
\end{tabular}




\begin{tabular}{|c|c|c|c|c|c|c|}
\hline Study & Study design & Country & Objective & $\begin{array}{l}\text { Duration } \\
\text { of study }\end{array}$ & Outcome & Ref. \\
\hline $\begin{array}{l}\text { Marzouk } \\
\text { et al }\end{array}$ & $\begin{array}{l}\text { Prospective } \\
\text { Comparative } \\
\text { Study }\end{array}$ & KSA & $\begin{array}{l}\text { Evaluate laparoscopic } \\
\text { appendectomy in } \\
\text { comparison with open } \\
\text { appendectomy, with } \\
\text { special emphasis on } \\
\text { postoperative septic } \\
\text { complications. }\end{array}$ & 5 Years & $\begin{array}{l}\text { The study found that laparoscopic } \\
\text { appendectomy is as safe and } \\
\text { effective as the open one, as it } \\
\text { significantly reduces the } \\
\text { postoperative infection rate. }\end{array}$ & 9 \\
\hline
\end{tabular}

Al-Bassam, however, tried prospectively to examine the efficacy, safety and complications of LA in children. Enrolled a total of 113 children according to specific criteria in the period between January 1999 and May 2003 at King Khalid University Hospital in Riyadh, Kingdom of Saudi Arabia. They found that Laparoscopic appendectomy is both a safe and effective method in managing children with acute uncomplicated appendicitis. LA should be done with caution in children with complicated appendicitis as will be further discussed later. 8

Marzouk et al group tried to evaluate laparoscopic appendectomy in comparison with open appendectomy, with special emphasis on postoperative septic complications. Their total study group included 227 consecutive patients admitted with suspected appendicitis in the period between 1995 and 1999. They found that wound infection was higher in OA than LA procedures, along with other factors making the laparoscopic procedure is as effective and safe as the open one. ${ }^{9}$

\section{DISCUSSION}

Acute appendicitis is one of the commonest clinical presentations that need emergent surgical intervention with $8 \%$ of lifetime incidence. ${ }^{1}$ Since Fitz firstly described it in 1886, a lot has been documented about the inflamed vermiform appendix as well as the need for medical intervention to prevent the morbid consequences of such cases. ${ }^{10}$ According to Bristow, appendectomy is the best way to manage appendicitis. ${ }^{11}$ Appendectomy has been favored because of its outcomes that directly reduce morbidity and mortality rates. McBurney has been credited the surgical technique of the open appendectomy in 1894 , which has not significantly changed in the last 120 years. $^{12}$

OA approaches can be briefly described as it involves making a $5 \mathrm{~cm}$ incision at the lateral border of the right rectus muscle at the midpoint between the umbilicus and right anterior-superior iliac spine. Blunt dissection and electrocautery are used to separate the fascia from muscles, and the peritoneum is then opened. The cecum then can be visualized and mobilized revealing the appendix. Cecum and appendix are then brought out of the peritoneal cavity, then the mesoappendix is ligated, and the appendiceal base is divided to leave a stump. ${ }^{13}$
Laparoscopic appendectomy was firstly described by Semm in 1983 with the advent of minimal being a minimally invasive procedure. Surgical operations have evolved over time from OAs to increasingly minimally invasive LA procedures and advancements in laparoscopic surgery and intraoperative instruments are markedly increased in the last decade. Such improvements are why LA is more preferred than the open technique.

In Saudi Arabia, the study of Nassir et al, focus was put mainly on different factors that might be affected by the type of procedure. However, 5.34\% of the undergone LA operations were converted to an open procedure due to inability to insufflate in $7.7 \%$ of those cases, $61.5 \%$ unclear anatomy or difficult dissection, the remaining $30.8 \%$ due to massive intra-operative bleeding. ${ }^{7}$

However, in Al-Bassam study, LA was successfully completed in only $88 \%$ of attempted LAs among patients and conversion to open appendectomy had to be restored to for complicated cases due to technical difficulties such as malposition of appendix, mass formation, adhesions and perforation during manipulation. ${ }^{8}$

In the study of Marzouk et al has shown that $48 \%$ of the patients that had undergone appendectomy had a laparoscopic approach while $52 \%$ had an open approach. The male-to-female ratio of the laparoscopic group was 2.4:1 and mean age group was 23 years while the OA group male-to-female ratio was 2.3:1 with a mean age of 20.2 years. ${ }^{9}$

Average age groups in Al-Bassam, and Nassir et al studies were 8 and 28 years, respectively, allowing this study to cover wider range of age groups and associated findings in each research. ${ }^{7,8}$

Mean operative time ( $\mathrm{min}$ ) in the laparoscopic procedures was $67.3 \pm 25.1$ for LA and $59.4 \pm 11.2$ for OA procedures in Marzouk et al study while in Al-Bassam study, which data is on laparoscopic appendectomy in children, the mean operative time was $53 \pm 24.41$ for uncomplicated appendicitis and $63.5 \pm 17.33$ for complicated appendicitis and it was about 80 mins in Nassir et al study, whose study group underwent laparoscopic appendectomy. This, in turn, makes OA a faster operation than LA in adults. ${ }^{7-9}$,

However, in Marzouk et al study, the mean hospital stay (days) among LA patients was $2.2 \pm 2.8$ and among OA 
patients $3 \pm 3.1$. Mean hospital stay in Al-Bassam study was $2.9 \pm 0.98$ for uncomplicated cases and $6.6 \pm 4.91$ for complicated ones. Moreover, the mean hospital stay in Nassir et al study was 2 days ranging from 2-4. Thus, mean hospital stay is significantly less in LA than OA patients. $^{7-9}$

Marzouk et al study has compared the prevalence of both, postoperative septic complications wound infection, and intra-abdominal infection among both LA and OA patients showing that $0 \%$ versus $7.6 \%$ suffered from wound infections in LA and OA cases, respectively, while $2.7 \%$ versus $2.5 \%$ suffered from intra-abdominal infection in LA and OA, respectively. Concluding that this might indicate higher rate of intra-abdominal infections in the LA patients than OA ones, while wound infections are mainly shown in OA cases. ${ }^{9}$

Al-Bassam has found that there were no cases of wound infection and intra-abdominal collections in the uncomplicated appendicitis LA procedures while $13 \%$ of the complicated appendicitis suffered wound infections and intra-abdominal collections. ${ }^{8}$

In Nassir et al study, 5.35\% suffered postoperative wound infections, along with $3.70 \%$ suffering intra-abdominal abscesses. ${ }^{7}$

Intra-abdominal abscess is a serious life-threatening complication. These findings are consistent with other studies that showed an increased risk of intra-abdominal abscess after laparoscopic surgery. ${ }^{14-16}$

A number of studies that were conducted worldwide were looked-into and revised carefully to check any odd findings that do not match most of the conducted research and the findings of this study are similar to the other findings. ${ }^{14-16}$

\section{Strengths}

During articles selection, studies were doubled-reviewed, and their results to assure that we enroll the studies related to the objective of our study, and to avoid or minimize errors in the results.

\section{Limitations}

We acknowledge some limitations we had in the making of this study. We tried to include articles that fit in the outcome criteria for inclusion into our review. Certainly, a bigger sample size would provide more significant results.

\section{CONCLUSION}

Overall, the study was to compare some variations concerning open versus laparoscopic appendectomy including mean operative time, mean hospital stay and prevalence of postoperative complications, mainly, wound infection and intra-abdominal infections. Mean operative time was shorter in open procedures than laparoscopic ones making OA the faster intervention. Mean hospital stay was found to be significantly less in LA than OA patients.

Indicated higher rate of intra-abdominal infections in the LA patients than OA ones, while wound infections are mainly present in OA cases in the reference studies.

Funding: No funding sources

Conflict of interest: None declared

Ethical approval: Not required

\section{REFERENCES}

1. Addiss DG, Shaffer N, Foweler BS, Tauxe R. The epidemiology of appendicitis and appendicectomy in the United States. Am J Epidemiology. 1990;132:910-25.

2. Chiarugi M, Buccianti P, Celona G, Decanini L, Martino MC, Goletti O, et al. Laparoscopic compared with open appendectomy for acute appendicitis: a prospective study. Eur J Surg. 1996;162:385-390.

3. Masoomi H, Nguyen NT, Dolich MO, Mills S, Carmichael JC, Stamos MJ. Laparoscopic Appendectomy Trends and Outcomes in the United States: data from the Nationwide Inpatient Sample (NIS), 2004-2011. Am Surg. 2014;80:1074-7.

4. Khan SY, Al-Balushi ZN, Bhatti KM, Ehsan T, Mandhan P. Cost Comparison between Laparoscopic and Open Appendectomies in Children. Sultan Qaboos University Med J. 2013;13(2):275-9.

5. Roses R, Paulson E, Kanchwala S, Morris J. "Appendectomy." Gowned and Gloved Surgery: Introduction to Common Procedures, 1st Edition, Elsevier Publisher; 2008: 123-130.

6. Litwin DE, Cahan Ma. Laparoscopic cholecystectomy. Surg Clin North Am. 2008;88:1295-313.

7. Nassir AY, Kashha AM, Altrabolsi AH, Ghannam AN, Sindi OA, Alzimaity AM. Laparoscopic Appendectomy between the Advantages and Complications: A Cross Section Study -Jeddah Saudi Arabia - 2016. The Egyptian J Hospital Med. 2017;67(2):660-5.

8. Al-Bassam AA. Laparoscopic appendectomy in children. Saudi Med J. 2004;26(4):556-9.

9. Marzouk M, Khater M, Elsadek M, Abdelmoghny A. Laparoscopic vs open appendectomy. Surg Endosc. 2003;17:721-4.

10. Fitz RH. Perforating inflammation of the vermiform appendix with special reference to its early diagnosis and treatment. Transactions Assoc Am Phys. 1886;1:107-44.

11. Bristow N. Treatment and management of acute appendicitis. Nurse Times. 2004;100(43):34-6. 
12. Switzer NJ, Gill RS, Karmali S. The evolution of the appendectomy: from open to laparoscopic to single incision. Scientifica (Cairo). 2012;895469.

13. Townsend CM, Ever B. Atlas of General Surgical Techniques, 2010.

14. Al-Mulhim AS, Al-Mulhim FM, Al-Suwaiygh AA, Al-Masaud NA. Laparoscopic versus open appendectomy in females with a clinical diagnosis of appendicitis. Saudi Med J. 2002;23(11):1339-42.

15. Shaikh AR, Sangrasi AK, Shaikh GA. Clinical Outcomes of laparoscopic versus open Appendectomy. JSLS. 2009; 13:574-80.
16. Agresta F, De Simone P, Leone L, Arezzo A, Biondi A, Bottero L, et al. Italian Society of Young Surgeons (SPIGC). Laparoscopic appendectomy in Italy: an appraisal of 26,863 cases. J Laparoendosc Adv Surg Tech A. 2004;14:1-8.

Cite this article as: Miftah M, Attiah J, Alawaji O, Alghamdi F, Alasmari A, Elsayed A, et al. Open versus laparoscopic appendectomy among Saudi patients. Int J Community Med Public Health 2018;5:3725-9. 